\title{
Performance and configuration analysis of tracking time anti- windup PID controllers
}

\author{
Muniru Olajide Okelola ${ }^{1}$, David Olugbenga Aborisade ${ }^{1}$, Philip Adesola Adewuyi ${ }^{2}$ \\ ${ }^{1}$ Faculty of Engineering, Ladoke Akintola University of Technology, P. M. B. 4000, Ogbomoso and 210214, Nigeria \\ ${ }^{2}$ College of Engineering, Bells University of Technology, P. M. B. 1015, Ota and 112212, Nigeria
}

\begin{abstract}
ARTICLE INFO
\section{Article history's:}

Received 29 November 2020

Revised 03 December 2020

Accepted 11 December 2020

\section{Keywords:}

Anti-windup,

Back-calculation,

Clamping,

Globe valve,

PID.

ABSTRACT

As popular as the application of Proportional Integral Derivative (PID) controller is, issues relating to saturation effects are still being addressed using different techniques. Saturation occurs when a system is experiencing integrator windup, that is, as the input saturates, integral error would be increasing. If the error decreases, the increased integral value prevents the PID controller from returning to normal operations. To overcome integrator windup, clamping and back-calculation anti-windup techniques with separate tracking time were applied. The advantage of separate tracking time is to freely adjust and monitor the time saturation would occur. The results obtained after simulation in MATLAB Simulink environment showed that both techniques gave similar outputs with a stable response of magnitude 0.95 at 1.5 seconds settling time when a unit step reference input signal was applied as compared to conventional PID controller which had an overshoot of 1.04 before settling at a magnitude of 1.0 which corresponding to a time of 1.5 seconds. Similar responses were obtained when outputs of the anti-windup controllers were combined to control the motorized globe valve. When the anti-windup controllers were cascaded, vibration, instability, and operational distortions occurred. This work has shown that windup phenomenon could be prevented using separate tracking anti-windup techniques and that anti-windup controllers are best configured in parallel for good response and not in cascade.
\end{abstract}

This work is licensed under a Creative Commons Attribution-Share Alike 4.0

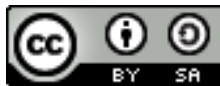

Philip Adesola Adewuyi,

Bells University of Technology, P. M. B. 1015, Ota and 112212, Nigeria

Email: solaadewuyi@gmail.com

\section{INTRODUCTION}

Windup is a phenomenon that occurs when a controller that possesses integral action receives an error signal for significant periods of time, the integral term of the controller would increase at a rate governed by the integral time of the controller [1][2][3][4][5]. In other words, windup phenomenon is the stagnancy in output quantity of a system irrespective of the increase in input quantity of that system due to continuous increase in error quantity in the system. This characteristic is referred to as integral windup and it is the actual factor that is responsible for unchanged output of a system despite increase in error value. Efforts to solve the windup problem have led to the emergence of several methods to prevent windup in any given system [6][7] [8][9].

This integral windup would eventually cause the manipulated variable to reach $100 \%$ (or $0 \%$ ) of its scale, that is, its maximum or minimum limits of saturated non-linearity behavior. This control system 'override' could lead to a sustained error. Override occurs when another controller takes over control of a particular loop [10]. The original controller remains switched on and still receives an error signal which through time, 'windup' the integral part until something is done to stop this occurring [11][12].

This windup phenomenon is explained from linear models with the assertion that windup occurs due to limitations in the actuator when it reaches the actuator limits [13][14][15][16]. As this occurs, the feedback path is broken and the system runs in open loop because the actuator will remain at its limit irrespective of the 
process output as long as the actuator is still saturated. This would lead to build up of integral term since the error would be typically zero.

This would make the integral term and the controller output relatively very large. This in turn would make the control signal saturated and proper anti-windup approach would be need to eliminate this saturation [17]. This would lead to large transient which is referred to as windup effect [18].

Saturation could be defined mathematically in terms of static nonlinearity of Figure 1 as (1).

$$
\operatorname{Sat}(u)=\left\{\begin{array}{cl}
U_{\min } & \text { if } u<u_{\min } \\
u & \text { if } u_{\min } \leq u \leq u_{\max } \\
u_{\max } & \text { if } u>u_{\max }
\end{array}\right.
$$

where, $u_{\min }$ and $u_{\max }$ are the minimum and maximum allowed actuation signals.

Now, if $u$ is a vector with $m$ components, the saturation function is defined as the saturation of all its components $\left(U_{\min }, U_{\max } \in \mathbb{R}^{m}\right)$ as contained in (2).

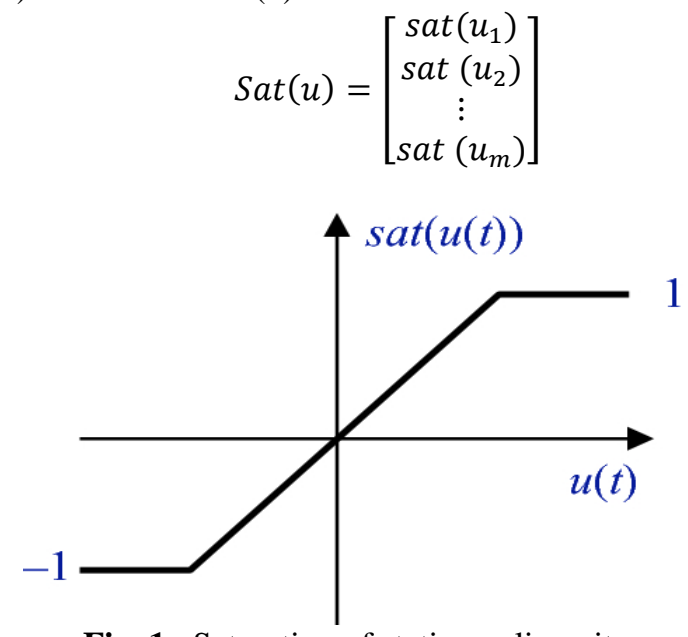

Fig. 1. Saturation of static nonlinearity

Part of the anti-windup approaches to mitigate this saturation effect is the use of model-reference adaptive control schemes with rate-limits [19]. Others are anti-windup schemes with tunable phase-shift which has been applied to correct windup phenomenon in voltage source converters. The performance obtained with this antiwindup scheme showed an improvement over the conventional PID scheme [20]. Voltage redistribution-based anti-windup scheme has also been used as a controller instead of traditional PID scheme to reduce the effect of saturation in the operation of an induction motor. This scheme could be applied to other areas of control as well [21]. An anti-windup scheme called "a newborn anti-windup" has also been used which focused on the state prediction of fractional integrator. Once the state is established, saturation could be easily controlled [22].

This research work attempts to mitigate the effect of windup as applied to a motorized globe valve and explore effect of having both clamping anti-windup and back-calculation anti-windup connected in cascade and when their outputs are combined to control the motorized globe valve. The rest of the paper is divided into research method/algorithm, results and discussion as well as conclusion.

\section{RESEARCH METHOD/ALGORITHM}

Proportional-Integral-Derivative (PID) controller still remains as the widely used controller for various applications in control system due to its simplicity [23]. Despite its popularity, PID controller exhibits windup phenomenon when the motor operates in a saturated state, which may cause degradation to the control system. In order to keep the windup effect at bay, some anti-windup techniques have been formulated such as; clamping algorithm anti-windup technique and back-calculation anti-windup technique.

\subsection{Clamping algorithm for PID}

This algorithm was introduced by Astrom and Wittenmark in [24]. This applies to PID control laws implemented in incremental form as given by (3):

$$
u((k+1))=u(k T)+\Delta u(k T)
$$

where

$$
\Delta u(k T)=u(k T)-u((k-1) T)
$$


From (4), integration is stopped by the addition of a new $\Delta u(k T)$ which causes a violation of the saturation band. This makes this technique produce no integration and seamless switching between automatic mode and manual mode.

According to [10], position digital PID control algorithm is given by (5).

$$
u(t)=k_{p}\left[e(t)+\frac{1}{T_{i}} \int_{0}^{t} e(t) d t+T_{d} \frac{d e(t)}{d t}\right]
$$

$k_{p}$ is proportional gain; $T_{i}$ is integral time constant; $u(t)$ is output control quantity; $e(t)$ is deviation;

$$
e(t)=r(t)-y(t)
$$

Therefore, the following approximate transformation is obtained from (6), resulting in (7) and (8).

$$
\begin{aligned}
& \int_{0}^{t} e(t) d t \approx T \sum_{0}^{k} e(i) \\
& \frac{d e(t)}{d t} \approx \frac{e(k)-e(k-1)}{T}
\end{aligned}
$$

Then, the differential equation of PID controller translates into (9) as:

$$
u(k)=k_{p} e(k)+k_{i} \sum_{0}^{k} e(i)+k_{d}[e(k)-e(k-1)]
$$

where,

$$
k_{i}=k_{p} \times \frac{T}{T_{i}} ; k_{d}=k_{p} \times \frac{T_{d}}{T}
$$

Since position is being controlled, outputs are related with the past state which would accumulate during computation [25]. Moreover, because the system output corresponds to the actual position of the actuator, failure of the system would cause substantial change in position of the actuator which could cause significant accidents. This shortcoming leads to clamping PID control algorithm.

From (9),

$$
u(k-1)=k_{p} e(k-1)+k_{i} \sum_{0}^{k-1} e(i)+k_{d}[e(k-1)-e(k-2)]
$$

By subtracting (11) from (9), (12) results:

$$
\Delta u(k)=u(k)-u(k-1)=k_{p}[e(k)-e(k-1)]+k_{i} e(k)+k_{d}[e(k)-2 e(k-1)+e(k-2)]
$$

From equation (4), kth PID controller output is given by (13).

$$
u(k)=\Delta u(k)+u(k-1)
$$

From (13) clamping PID control algorithm needs to reserve the value of the first two moments' deviation. Therefore, three factors are important in clamping algorithm:

i. limitation of the PID regulator output, that is, when $u(k)>u_{\max }$, assume $u(k)= \pm u_{\max }$;

ii. carrying out of the integral operation separately, $|e(k)|>e_{p}$, when deviation is large, $\mathrm{P}$ control is applied $|e(k)| \leq e_{p}$, when deviation is small, PI control is applied.

iii. weakening of the integral method as the process approaches maximum limit.

That is;

If $u(k-1)>u_{p}$, the system is made to accumulate negative bias;

If $u(k-1) \leq u_{p}$, the system is made to accumulate positive bias [26].

\subsection{Back-calculation anti-windup with separate tracking time algorithm} as (14):

The basis of this model is the conventional PID controller according to [27] [28] [29] [30] which is given

$$
G_{1}(s)=k_{p}+\frac{k_{i}}{S}+k_{d} S
$$

where, $k_{p}$ is the proportional gain. $k_{i}$ is the integral gain. $k_{d}$ is the derivative gain.

The anti-windup scheme to be developed in line with the design objectives as touching the limiter are related by (15),

$$
U_{o}=\left\{\begin{array}{c}
U_{m a}, \quad \text { if } U \geq U_{m a} \\
U, \quad \text { if } U_{m i} \leq U \leq U_{m a} \\
U_{m i}, \text { if } U \leq U_{m i}
\end{array}\right.
$$

$U_{o}$ is the limiter's output, $U_{m a}$ is the maximum output value of the limiter, and $U_{m i}$ is the minimum output value of the limiter. $U$ is the input value of the limiter.

From (14), the integral term is written in form of integral time constant, tracking time and input value of the limiter as contained in (16). Therefore, 


$$
\frac{K_{i}}{S} \equiv e_{i}=\frac{K_{p}}{T_{i}} e+\frac{1}{T_{t}}\left(U-U^{\prime}\right)
$$

where, proportional gain is $K_{p}$, integral time constant is $T_{i}$, tracking time constant is $T_{t}, U^{\prime}$ is the process input, and $U$ is the controller output and $e_{i}$ is the integral term.

In order to reset the integral term, $T_{t}$ is adjusted using (17) where $T_{d}$ is the derivative time.

$$
T_{t}=\sqrt{ }\left(T_{i} \times T_{d}\right)
$$

Taking Laplace transform of (16) and substituting in (14) results in (18)

$$
G_{1}(S)=\frac{K_{p} T_{i} T_{t}+K_{p} T_{t} e+T_{i}\left(U-U^{\prime}\right)+K_{d} T_{i} T_{t}}{T_{i} T_{t}}
$$

Separating into like terms results in (19).

$$
G_{1}(S)=\frac{\left[K_{p} T_{i}+E(S)+K_{d} T_{i}\right]}{T_{i}}+\frac{U(S)-U^{\prime}(S)}{T_{i} T_{t}}
$$

From (19)

$$
G_{1}(S)=K_{p} K_{d}+\frac{E(S)}{T_{i}}+\frac{U(S)-U^{\prime}(S)}{T_{i} T_{t}}
$$

Since, $(S) \approx U(S)-U^{\prime}(S)$

Equation (20) could be written as (21).

$$
G_{1}(S)=K_{p} K_{d}+\frac{U(S)-U^{\prime}(S)}{T_{i}}+\frac{U(S)-U^{\prime}(S)}{T_{i} T_{t}}
$$

Letting,

$$
{ }^{\prime} a^{\prime}=K_{p} K_{d},{ }^{\prime} b^{\prime}=\frac{U(S)-U^{\prime}(S)}{T_{i}}, \text { and }^{\prime} c^{\prime}=\frac{U(S)-U^{\prime}(S)}{T_{i} T_{t}}
$$

Comparing ' $b$ ' and ' $c$ ', the effect of saturation would be reduced by $T_{t}$ factor in ' $c$ ', thus preventing the actuator from reaching full saturation.

This is the premise on which the back-calculation anti-windup with separate tracking time performs.

\subsection{Simulation parameters used}

The motorized globe valve model used is given by (22) which is formulated from physical parameters of a brushless direct current motor and globe valve.

$$
G T=\frac{1.87}{7.33 e-08 S^{4}+0.0002368 S^{3}+0.2743 S^{2}+20.09 S+100}
$$

The stability of the motorized globe valve model was tested using root locus technique. The result obtained as contained in Figure 2 indicates the system is stable as all the poles are on the left-hand side of the s-plane.

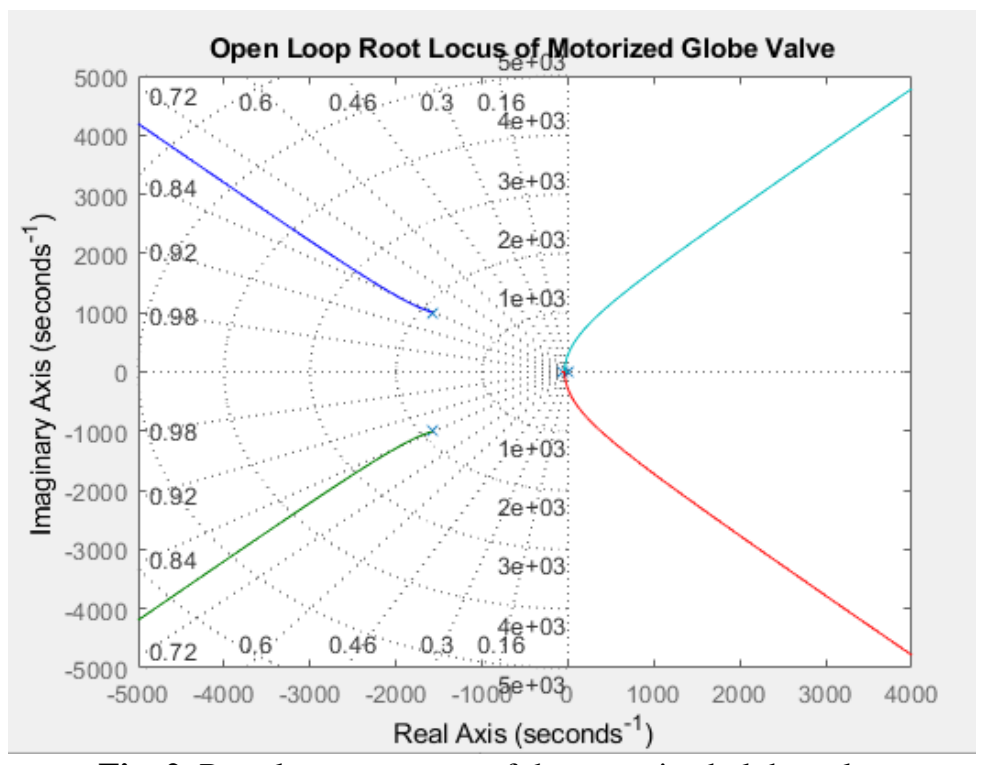

Fig. 2. Root locus response of the motorized globe valve 
The Proportional Integral Derivative (PID) controller used was auto-tuned in MATLAB and the simulation parameters obtained are displayed in Table 1 and Table 2. The performance and robustness parameter of the PID is shown in Table 2. For the PID tracker, the auto-tuned results for both clamping and back-calculation anti-windup techniques were the same as displayed in Table 3 and Table 4. Resulting performance and robustness parameters are given in Table 4. The obtained parameters were thereafter used for simulations of various configurations that were under investigation in MATLAB Simulink environment.

Table 1. PID tuned parameter results

\begin{tabular}{lll}
\hline & Tuned & Block \\
\hline $\mathrm{P}$ & 92.67 & 1 \\
$\mathrm{I}$ & 858.8311 & 1 \\
$\mathrm{D}$ & 0.50808 & 0 \\
$\mathrm{~N}$ & 18.5682 & 100 \\
\hline
\end{tabular}

Table 2. Performance and robustness parameters

\begin{tabular}{lll}
\hline & Tuned & Block \\
\hline Rise time & $0.133 \mathrm{~s}$ & $119 \mathrm{~s}$ \\
Settling time & $0.536 \mathrm{~s}$ & $212 \mathrm{~s}$ \\
Overshoot & $7.27 \%$ & $0 \%$ \\
Peak & 1.07 & 1 \\
Gain margin & $40.7 \mathrm{~dB} @$ & $81.5 \mathrm{~dB} @ 289 \mathrm{rad} / \mathrm{s}$ \\
& $278 \mathrm{rad} / \mathrm{s}$ & $90.9 \mathrm{deg} @ 0.0187 \mathrm{rad} / \mathrm{s}$ \\
Phase margin & $69 \mathrm{deg} \mathrm{@}$ & \\
& $10.8 \mathrm{rad} / \mathrm{s}$ & Stable \\
\hline
\end{tabular}

Table 3. Clamping and back-calculation tuned results

\begin{tabular}{lll}
\hline & Tuned & Block \\
\hline $\mathrm{P}$ & 92.67 & 6.4811 \\
$\mathrm{I}$ & 858.8311 & 17.1392 \\
$\mathrm{D}$ & 0.50808 & -0.43475 \\
$\mathrm{~N}$ & 18.5682 & 5.3964 \\
\hline
\end{tabular}

Table 4. Performance and robustness parameters for clamping and back-calculation anti-windup

\begin{tabular}{lll}
\hline & Tuned & Block \\
\hline Rise time & $0.133 \mathrm{~s}$ & $7.16 \mathrm{~s}$ \\
Settling time & $0.536 \mathrm{~s}$ & $21.8 \mathrm{~s}$ \\
Overshoot & $7.27 \%$ & $0 \%$ \\
Peak & 1.07 & 0.999 \\
Gain margin & $40.7 \mathrm{~dB} @$ & $68.5 \mathrm{~dB} @ 277 \mathrm{rad} / \mathrm{s}$ \\
Phase margin & $278 \mathrm{rad} / \mathrm{s}$ & $93.2 \mathrm{deg} @ 0.323 \mathrm{rad} / \mathrm{s}$ \\
& $69 \mathrm{deg} \mathrm{@}$ & \\
Closed-loop stability & $10.8 \mathrm{rad} / \mathrm{s}$ & Stable \\
\hline
\end{tabular}

\subsection{Simulation setup}

The simulation is setup as displayed in Figure 3 for comparison amongst, uncontrolled system, conventional PID, clamping, and back-calculation controllers. Figure 4 is the simulation arrangement for the addition of clamping controller and back-calculation controller. Figure 5 is the simulation cascade arrangement for clamping controller and back-calculation controller. 


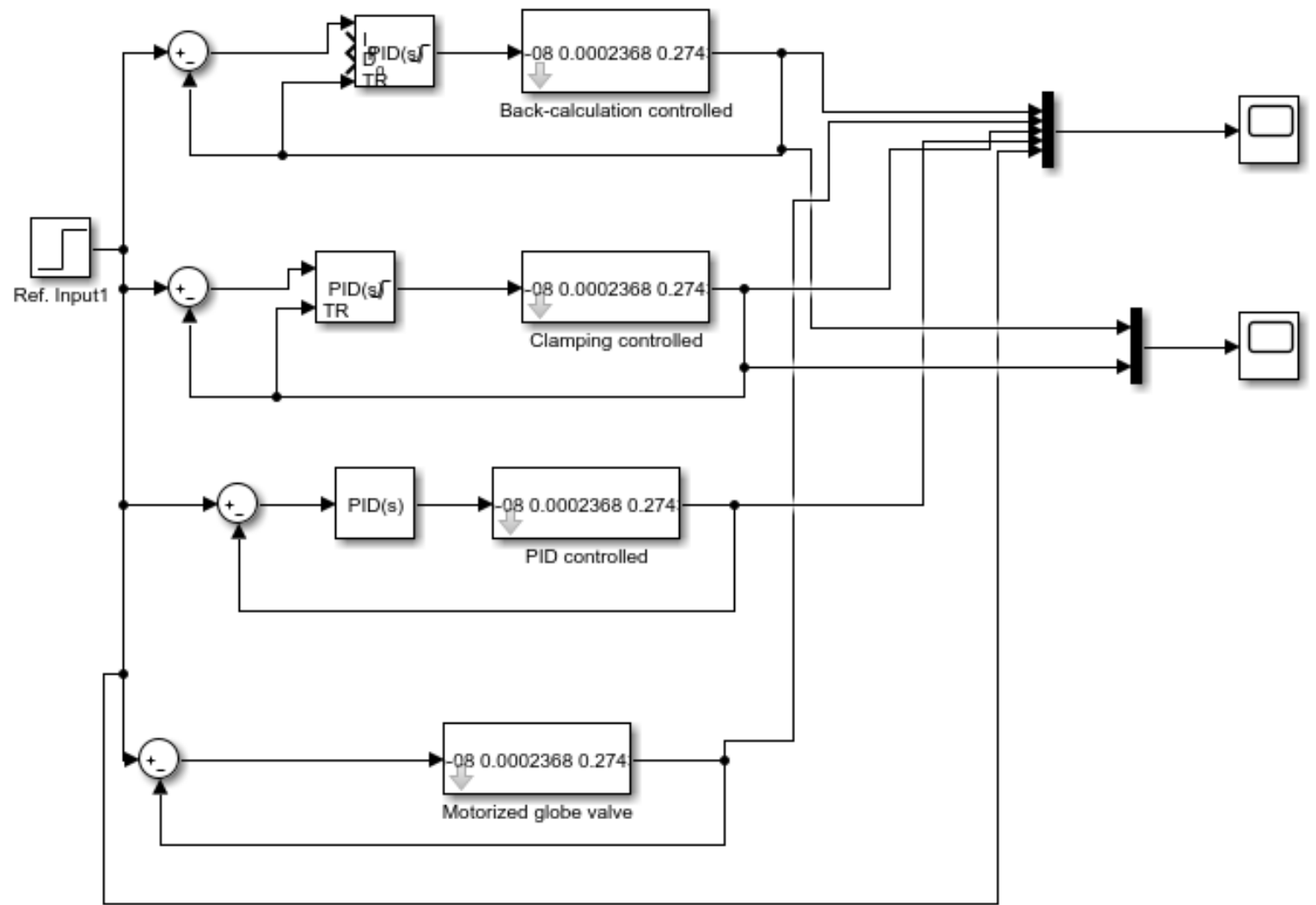

Fig. 3. MATLAB Simulink arrangement of the anti-windup scheme

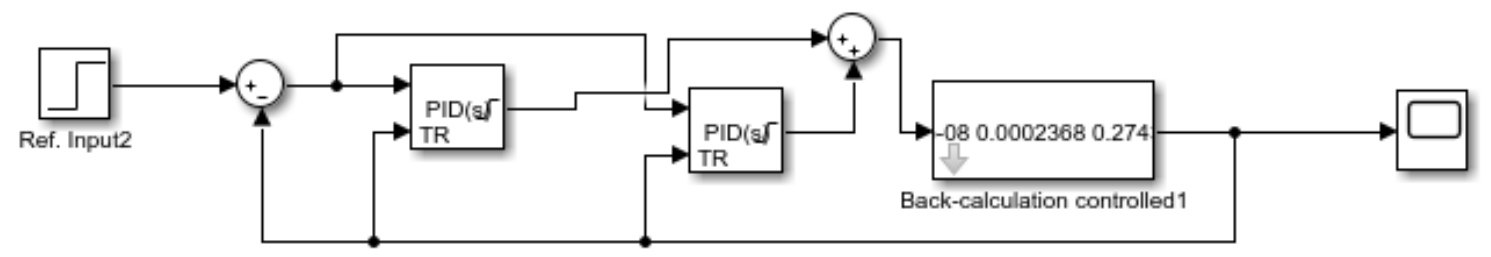

Fig. 4. MATLAB Simulink arrangement for combined controllers' output

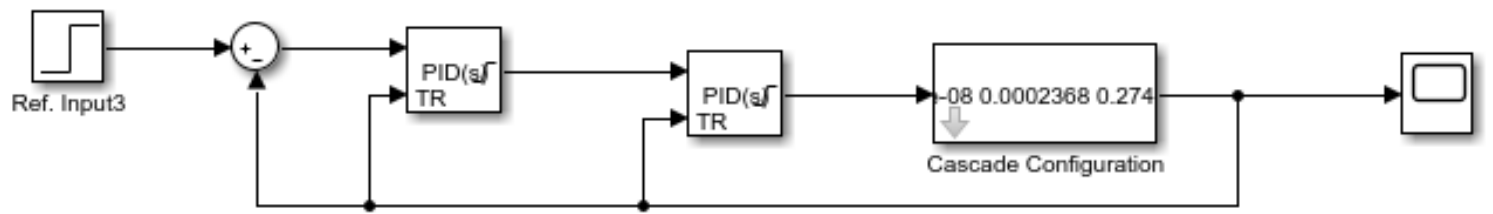

Fig. 5. MATLAB Simulink cascade arrangement of the anti-windup schemes

\section{RESULTS AND DISCUSSION}

\subsection{Case 1}

The results obtained are shown in Figure 6. The resulting curves displayed shows that for the uncontrolled motorized globe valve, does not follow the reference input signal as it peaks at 0.01 with a time delay of $0.1 \mathrm{~s}$. This result of the uncontrolled globe valve is unacceptable as its performance indicates an operational inefficiency. For such a system operation, short term effect is continuous repair due to frequent breakdown. In order to mitigate this effect, a conventional PID controller is used to control the operation of the motor. The result obtained due to PID controller show a delay in response time of $0.1 \mathrm{~s}$ also. It has an overshoot of magnitude 1.08 and settling time of $1.5 \mathrm{~s}$. Then, when clamping anti-windup controller is applied to the motorized globe valve model, it is observed that there is no overshoot in relation to the reference input signal but has a rise time of $1.2 \mathrm{~s}$ and settling time of $1.5 \mathrm{~s}$ and the output magnitude of the settled signal is 0.95 as 
compared to the reference signal magnitude value of 1 . The same result is obtained for the back-calculation anti-windup controller for this application. For both clamping and back-calculation controllers, the output magnitude is pegged at 0.95 due to the need to prevent the integral part of the PID controller, in this instance, with tracking functionality, from reaching the maximum that could have led to saturation as experienced with the conventional PID controller.

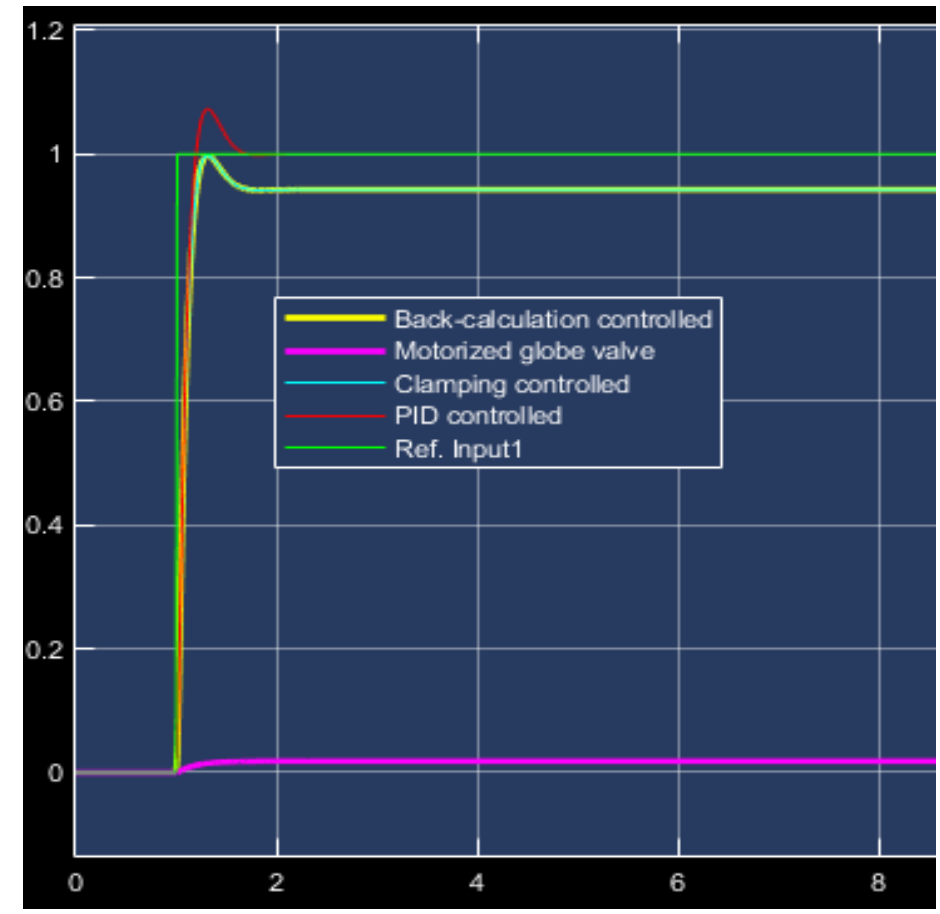

Fig. 6. Simulation results

\subsection{Case 2}

It was desired that the clamping anti-windup controller be cascaded with the back-propagation antiwindup controller in order to obtain an improved result. Having carried out the cascading of the two controllers, Figure 7 resulted. This is an indication that the two anti-windup controllers could not be cascaded when improved output is desired. The result shows the presence of critical instability, noise, and vibration. So, the two should be independent of the other and used according to the peculiarities of the system at hand.

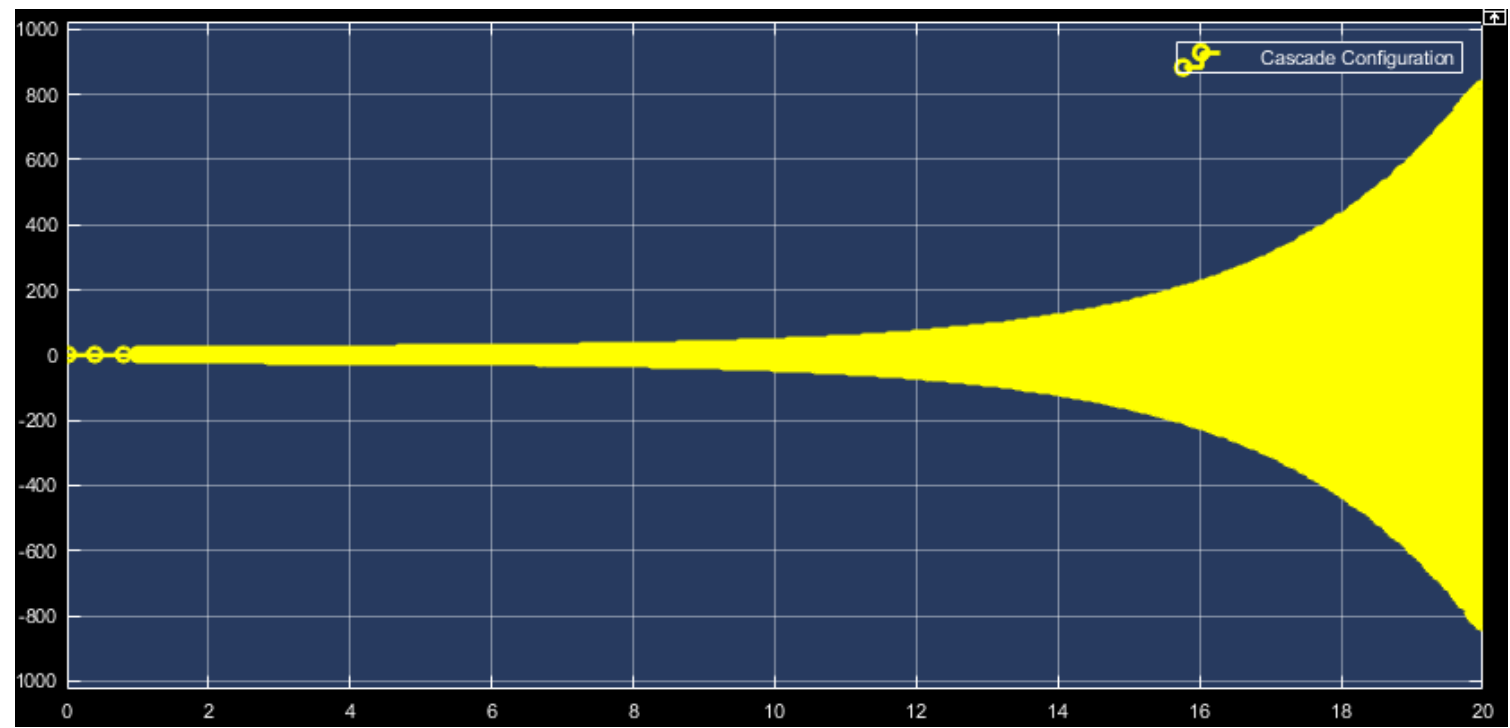

Fig. 7. Signal distortion due to cascading of back-calculation and clamping anti-windup techniques 


\subsection{Case 3}

Figure 8 shows the case of combining the outputs of both clamping controller and back-calculation controller and using the result to control the motorized globe valve. The output is not different from the case of individual anti-windup controllers as displayed in Figure 6. So, combination of outputs due to clamping controller and back-calculation controller is not necessary as this could lead to undue loading of the system that could lead to more energy demand of the concerned system.

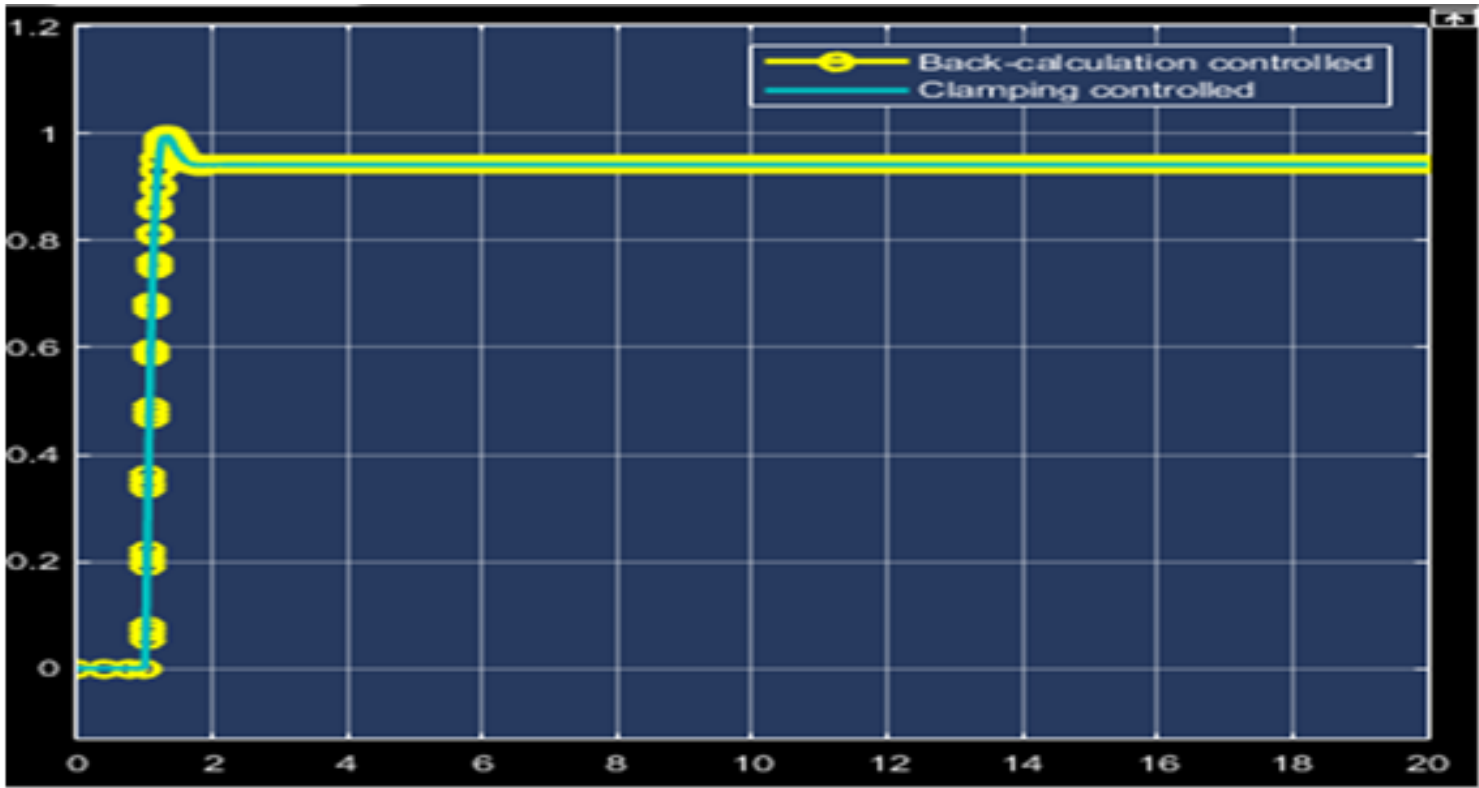

Fig. 8. Response of outputs addition due to back-calculation and clamping anti-windup techniques

\section{CONCLUSION}

Clamping anti-windup and back-calculation anti-windup techniques with separate tracking time have been applied to a model of motorized globe valve. The performance results obtained indicate that the effect of saturation due to the integral term of the PID control action has been eliminated. Also, when the results due to both anti-windup controllers were compared, there was no difference in their output responses, that is, rising time, settling time and overshoot were all the same. Further investigation as to whether the output would improve when the two anti-windup systems were cascaded showed that rather than improvement, vibration, distortion, and instability of the resulting system were recorded. However, when the outputs due to the two anti-windup controllers were combined to control the motorized globe valve, the same results were obtained as to when the individual anti-windup controller was applied.

Overall, the two anti-windup techniques for this application should not be cascaded. There is no need of combining the outputs due to the two anti-windup controllers for this application as there is no difference in the magnitude of 0.95 obtained when compared with the reference input signal of 1.0 supplied in all the three anti-windup configurations. It was only the conventional PID controller response that had an overshoot before settling to a magnitude of 1.0 at 1.5 seconds. Further studies could look into how to improve the responses due to both clamping anti-windup and back-calculation anti-windup in order to follow closely that of the reference input without compromising the integrity of the anti-windup phenomenon.

\section{REFERENCES}

[1] D. Kumar, R. A. Gupta, and N. Gupta, "Minimization of current ripple and overshoot in four switch three-phase inverter fed BLDC motor using tracking anti-windup PI controller," in 2017 IEEE International Conference on Signal Processing, Informatics, Communication and Energy Systems (SPICES), 2017. DOI: https://doi.org/10.1109/SPICES.2017.8091355

[2] G. S. John and A. T. Vijayan, "Anti-windup PI controller for speed control of brushless DC motor," in 2017 IEEE International Conference on Power, Control, Signals and Instrumentation Engineering (ICPCSI), 2017. DOI: https://doi.org/10.1109/ICPCSI.2017.8391874

[3] R. Paull and N. Afroz, "Anti-windup FOPI controller for step motor," in 2018 2nd International Conference on Electronics, Materials Engineering \& Nano-Technology (IEMENTech), $2018 . \quad$ DOI: https://doi.org/10.1109/IEMENTECH.2018.8465253 
[4] F. Taheriyan, M. Teshnehlab, and S. Gharibzadeh, "Presenting a Neuroid model of wind-up based on dynamic synapse," J. Theor. Biol., vol. 465, pp. 45-50, 2019. DOI: https://doi.org/10.1016/j.jtbi.2019.01.018

[5] Y. Lv, J. Fu, G. Wen, T. Huang, and X. Yu, "On consensus of multiagent systems with input saturation: Fully distributed adaptive antiwindup protocol design approach," IEEE Trans. Control Netw. Syst., vol. 7, no. 3, pp. 1127 1139, 2020. DOI: https://doi.org/10.1109/TCNS.2020.2964146

[6] A. A. Adegbege and W. P. Heath, "A framework for multivariable algebraic loops in linear anti-windup implementations," Automatica (Oxf.), vol. 83, pp. $\quad 81-90, \quad 2017 . \quad$ DOI: https://doi.org/10.1016/j.automatica.2017.05.009

[7] A. Hauswirt, F. Dorfler, and A. Teel, "On the robust implementation of projected dynamical systems with anti-windup controllers," in 2020 American Control Conference (ACC), 2020. DOI: https://doi.org/10.23919/ACC45564.2020.9147378

[8] M. C. Turner, "Positive $\mu$ modification as an anti-windup mechanism," Syst. Control Lett., vol. 102, pp. 15-21, 2017. https://doi.org/10.1016/j.sysconle.2017.01.003

[9] A. Akram, M. Hussain, N. us Saqib, and M. Rehan, "Dynamic anti-windup compensation of nonlinear time-delay systems using LPV approach," Nonlinear Dyn., vol. 90, no. 1, pp. 513-533, 2017. DOI: https://doi.org/10.1007/s11071-017-3678-8

[10] A. Imami and M. Montazeri-Gh, "Stability analysis of override logic system containing state feedback regulators and its application to gas turbine engines," European Journal of Control, vol. 52, pp. 97-107, 2020. DOI: https://doi.org/10.1016/j.ejcon.2019.09.003

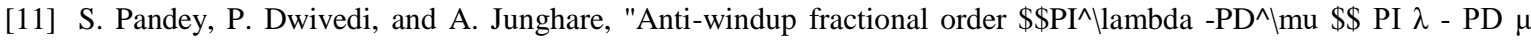
controller design for unstable process: A magnetic levitation study case under actuator saturation," Arab. J. Sci. Eng., vol. 42, no. 12, pp. 5015-5029, 2017. DOI: https://doi.org/10.1007/s13369-017-2535-x

[12] C. Luo, "Series fuzzy PID with anti-windup controller for intelligent vehicle," in SAE Technical Paper Series, 2020. DOI: https://doi.org/10.4271/2020-01-0113

[13] P. Ghignoni, N. Buratti, D. Invernizzi, and M. Lovera, "Anti-windup design for directionality compensation with application to quadrotor UAVs," IEEE Control Syst. Lett., pp. 1-1, 2020. DOI: https://doi.org/10.1109/LCSYS.2020.3001881

[14] J. Busek, T. Vyhlidal, and P. Zitek, "IAE based tuning of controller anti-windup schemes for first order plus deadtime system," in 2017 21st International Conference on Process Control (PC), 2017. DOI: https://doi.org/10.1109/PC.2017.7976182

[15] A. Oveisi and T. Nestorović, "Vibration control subjected to windup problem: An applied view on analysis and synthesis with convex formulation," Control Eng. Pract., vol. 82, pp. 50-71, 2019. DOI: https://doi.org/10.1016/j.conengprac.2018.09.020

[16] A. Cristofaro, S. Galeani, S. Onori, and L. Zaccarian, "A switched and scheduled design for model recovery antiwindup of linear plants," Eur. J. Control, vol. 46, pp. 23-35, 2019. DOI: https://doi.org/10.1016/j.ejcon.2018.04.002

[17] T. Benjanarasuth, "Simplified controller design for output performance under common input limitations with generalized integral anti-windup for a class of processes," ASEAN Engineering Journal, vol. 10, no. 1, pp. 64-78, 2020. DOI: https://doi.org/10.11113/aej.v10.15543

[18] W. Shuang, S. Zhang, X. Wu, E.-J. Van Kampen, and Q. P. Chu, "An anti-windup fault tolerant control scheme with guaranteed transient performance for tailless flying wing aircrafts," in AIAA Guidance, Navigation, and Control Conference, 2017. DOI: https://doi.org/10.2514/6.2017-1253

[19] M. C. Turner, J. Sofrony, and E. Prempain, "Anti-windup for model-reference adaptive control schemes with ratelimits," Syst. Control Lett., vol. 137, no. 104630, p. 104630, $2020 . \quad$ DOI: https://doi.org/10.1016/j.sysconle.2020.104630

[20] E. Tomaszewski and J. Jiangy, "An Anti-Windup Scheme for Proportional Resonant controllers with tuneable phaseshift in Voltage Source Converters," in 2016 IEEE Power and Energy Society General Meeting (PESGM), 2016. DOI: https://doi.org/10.1109/PESGM.2016.7741367

[21] B. Wang, X. Zhang, Y. Yu, J. Zhang, H. Cai, and D. Xu, "Voltage redistribution-based anti-windup scheme for induction motor current controller in the field-weakening region," in 2019 IEEE Applied Power Electronics Conference and Exposition (APEC), 2019. DOI: https://doi.org/10.1109/APEC.2019.8722159

[22] S. Pandey, P. Dwivedi, and A. Junghare, "A newborn anti-windup scheme based on state prediction of fractional integrator for variable speed motor," in 2017 17th International Conference on Control, Automation and Systems (ICCAS), 2017. DOI: https://doi.org/10.23919/ICCAS.2017.8204312

[23] S. Ma et al., "RBF-network-based predictive ship course control," in 2020 Chinese Control And Decision Conference (CCDC), 2020. DOI: https://doi.org/10.1109/CCDC49329.2020.9164344

[24] Y. Yang and F. Gao, "Adaptive control of the filling velocity of thermoplastics injection molding," Control Eng. Pract., vol. 8, no. 11, pp. 1285-1296, 2000. DOI: https://doi.org/10.1016/S0967-0661(00)00060-5

[25] R. Lucian, C. C. Rodolfo, and E. N. Julio, "Analysis of Anti-windup Techniques in PID Control of Process with Measurement Noise," IFAC PapersOnline, vol. s. 51, pp. 948-953, 2018. DOI: https://doi.org/10.1016/j.ifacol.2018.06.100

[26] E.-S. Jun and S. Kwak, "A highly efficient single-phase three-level neutral point clamped (NPC) converter based on predictive control with reduced number of commutations," Energies, vol. 11, no. 12, p. 3524, 2018. DOI: https://doi.org/10.3390/en11123524 
[27] K. S. Rajesh and S. S. Dash, "Load frequency control of autonomous power system using adaptive fuzzy based PID controller optimized on improved sine cosine algorithm," J. Ambient Intell. Humaniz. Comput., vol. 10, no. 6, pp. 2361-2373, 2019. DOI: https://doi.org/10.1007/s12652-018-0834-Z

[28] Y. Wang, Q. Jin, and R. Zhang, "Improved fuzzy PID controller design using predictive functional control structure," ISA Trans., vol. 71, pp. 354-363, 2017. DOI: https://doi.org/10.1016/j.isatra.2017.09.005

[29] C. Soon, R. Ghazali, H. I. Jaafar, and S. Y. S. Hussien, "Sliding mode controller design with optimized PID sliding surface using particle swarm algorithm," Procedia Comput. Sci., vol. 105, pp. 235-239, 2017. DOI: https://doi.org/10.1016/j.procs.2017.01.216

[30] D. Somwanshi, M. Bundele, G. Kumar, and G. Parashar, "Comparison of fuzzy-PID and PID controller for speed control of DC motor using LabVIEW," Procedia Comput. Sci., vol. 152, pp. 252-260, 2019. DOI: https://doi.org/10.1016/j.procs.2019.05.019

\section{BIOGRAPHY OF AUTHORS}

Muniru Olajide Okelola is a senior lecturer in the Department of Electronic and Electrical Engineering at Ladoke Akintola University of Technology, Ogbomoso, Nigeria. His research interests are in the area of power system analysis, power and machine, and general electrical engineering.

David Olugbenga Aborisade is a Professor of Image processing and control systems in the Department of Electronic and Electrical Engineering at Ladoke Akintola University of Technology, Ogbomoso, Nigeria. He has published widely in the area of control systems and image processing, fuzzy logic controller, neuro-fuzzy logic controller, and application of AI to industrial operations.

Philip Adesola Adewuyi is a lecturer at the College of Engineering, Bells University of Technology, Ota, Nigeria. His research interests are in the area of control systems, neural network, fuzzy logic-based controllers, smart systems, robotics, and control of renewable energy devices. 